\title{
Protein $C$ preserves microcirculation in a model of neonatal septic shock
}

\author{
This article was published in the following Dove Press journal: \\ Vascular Health and Risk Management \\ 9 September 2009 \\ Number of times this article has been viewed
}

\author{
Doris Fischer' \\ Marcel F Nold ${ }^{2}$ \\ Claudia A Nold-Petry ${ }^{2}$ \\ Antonio Furlan ${ }^{2}$ \\ Alex Veldman ${ }^{3}$ \\ 'Department of Pediatrics, Hospital \\ of the JW Goethe University, \\ Frankfurt, Germany; ${ }^{2}$ Division \\ of Infectious Diseases, University \\ of Colorado Denver, Aurora, CO, \\ USA; ${ }^{3}$ Monash Newborn, Monash \\ Medical Centre, Melbourne, VIC, \\ Australia
}

Objectives: Sepsis remains a disease with a high mortality in neonates. Microcirculatory impairment plays a pivotal role in the development of multiorgan failure in septic newborns. The hemodynamic effects of recombinant activated protein $\mathrm{C}$ ( $\mathrm{rhAPC}$ ) were tested in an animal model of neonatal septic shock focusing on intestinal microcirculation.

Materials and methods: Endotoxic shock was triggered by intravenous application of Escherichia coli lipopolysaccarides in newborn piglets. Thereafter, five animals received a continuous infusion of $24 \mu \mathrm{g} / \mathrm{kg} / \mathrm{h}$ rhAPC, and five received vehicle for control. Over the course of three hours, intestinal microcirculation was assessed by intravital microscopy every $30 \mathrm{~min}$. Macrocirculation and blood counts were monitored simultaneously.

Results: After a short hypotensive period in all animals, the arterial blood pressure returned to baseline in the rhAPC-treated piglets, whereas the hypotension became increasingly severe in the controls. By 90 min, mean blood pressure in the controls was significantly lower than in the treatment group. Similar observations were made regaring microcirculation. After an early impairment in all study animals, functional capillary density and intestinal microcirculatory red blood cell velocity and red blood cell flow recovered in the rhAPC group, but deteriorated further in the control piglets.

Conclusion: Recombinant activated protein $\mathrm{C}$ protects macro- and microcirculation from endotoxic shock.

Keywords: protein C, neonatal septic shock, microcirculation, intravital microscopy

\section{Introduction}

Sepsis is one of the leading causes of death in hospitalized neonates and preterm infants. ${ }^{1}$ Sepsis results from a systemic response to infection, which can be triggered by components of the microbial cell wall or microbial DNA among others. These nonself patterns are detected by pattern-recognition receptors (PRRs) such as Toll-like receptors (TLRs). Upon ligand binding, TLRs induce pro-inflammatory cytokines (eg, tumor necrosis factor- $\alpha[$ TNF $\alpha]$, interleukin-1 [IL-1], IL-6, IL-8), which in turn activate coagulation and suppress fibrinolysis by stimulating the surface expression of tissue factor on monocytes and endothelium. Subsequently, thrombin is generated which leads to deposition of fibrin, disruption of the endothelial coagulatory equilibrium, and ultimately in microvascular thrombosis. ${ }^{2}$ On the basis of the molecular mechanisms involved in sepsis, it seems likely that therapeutic interventions and drugs targeting the interface of coagulation and inflammation may improve microcirculation and microvascular blood flow.
JW Goethe University Hospital, Dept.

of Pediatrics, Theodor Stern Kai 7, 60590

Frankfurt, Germany

$\mathrm{Tel}+496963015524$

Fax +4969630I 4757

Email doris.fischer@kgu.de 
The protein $\mathrm{C}$ pathway is one of the major mechanisms reining hemostasis. The zymogen protein $\mathrm{C}$ is activated by the thrombin-thrombomodulin complex in combination with the endothelial protein $\mathrm{C}$ receptor (EPCR). Activated protein $\mathrm{C}$ (APC) exerts its anticoagulatory effect by proteolytically degrading factors Va and VIIIa, and via facilitation of fibrinolysis through inhibition of tissue plasminogen activator inhibitor (PAI). APC also has an important anti-inflammatory role as illustrated by its amelioration of the inflammatory activation that occurs upon intravenous infusion of Escherichia coli; $;^{3}$ APC exerts this effect by inhibiting the liberation of TNF $\alpha$ and other pro-inflammatory cytokines through blocking nuclear factor- $\kappa \mathrm{B}(\mathrm{NF}-\kappa \mathrm{B})$ and p38 mitogen-activated protein kinase activation. ${ }^{4-7}$

Protein $\mathrm{C}$ is commercially available as recombinant human APC (rhAPC; Xigris ${ }^{\circledR}$, Eli Lilly, Indianapolis, IN, USA) or as the nonactivated zymogen human protein $\mathrm{C}$ (hPC; Ceprotin $^{\circledR}$, Baxter, Glendale, CA, USA). A large multicenter trial (PROWESS) showed a benefit for adult patients with severe sepsis who were treated with rhAPC. ${ }^{8}$ However, a multicenter trial in which rhAPC was administered to septic children was terminated because of an increased incidence in intracranial hemorrhage, especially in the subgroup of children younger than 60 days. ${ }^{9}$ As a result, the use of rhAPC in septic neonates is still limited and no multicenter trial data is available. Nonetheless, single-case reports describe the use of rhAPC in septic neonates. ${ }^{10-12}$ In addition, a beneficial effect of rhAPC in an animal model of neonatal ischemic brain injury has been reported. ${ }^{13}$ Another publication by our group demonstrated that the nonactivated zymogen protein $\mathrm{C}$ in neonatal septic shock was effective. ${ }^{14}$ Low protein $\mathrm{C}$ plasma levels have been identified as a predictor for increased mortality in the neonatal sepsis by Venkataseshan and colleagues. ${ }^{15}$

Studies investigating the molecular basis of inflammation have demonstrated increased production of pro-inflammatory mediators such as prostaglandins, nitric oxide, IL-1, and TNF $\alpha$. The release of these pro-inflammatory mediators can result in a vasodilatory/vasoconstrictory imbalance and subsequent microcirculatory impairment that improves after the application of rhAPC in an animal model of septic shock. ${ }^{16}$ Since microcirculation is one of the aspects of sepsis that has received less attention than others, we designed a study which focused on the important pathophysiological problem of microcirculatory impairment during septic shock. We hypothesized that treatment with rhAPC at least partly reverses these deleterious effects of endotoxemia. To investigate this hypothesis, we measured several parameters of macro- and microcirculation in a model of neonatal endotoxic shock in which piglets were challenged with lipopolysaccharide (LPS).

\section{Methods}

\section{Intravital microscopy}

The use of orthogonal polarization spectral imaging (OPS imaging; Cytoscan ${ }^{\circledR}$, Cytometrics, Philadelphia, PA, USA) as a noninvasive method of microcirculatory assessment in preterm and term infants has been described by GenzelBoroviczeny. ${ }^{17}$ OPS imaging is a microscopic approach based on epi-illumination with polarized light. ${ }^{18} \mathrm{~A}$ virtual light source is created at a depth of about $1 \mathrm{~mm}$ within the tissue through the use of special optics. The light shining through the tissue is absorbed by hemoglobin, yielding an image of the illuminated vessel in negative contrast with a resolution of 1 pixel $=1 \mu \mathrm{m}$. Fluorescent dyes are not necessary. Capillary red blood cell velocity (RBCV) is directly measured, whereas functional capillary density (FCD) and capillary red blood cell flow (FRBC) are calculated. Functional capillary density $\left(\mathrm{FCD}\left[\mathrm{cm} / \mathrm{cm}^{2}\right]\right)$ represents the fraction of capillaries that are perfused compared to all capillaries in a defined region of interest. Capillary red blood cell flow (FRBC $\left[\mu \mathrm{m}^{3} / \mathrm{sec}\right]$ ) is calculated from the capillary diameter and red blood cell velocity $(\mathrm{VRBC}[\mu \mathrm{m} / \mathrm{sec}])\left(\mathrm{FRBC}=\pi / 4 \times \mathrm{D}^{2} \times \mathrm{RBCV}\right) .{ }^{19}$ Using OPS imaging, it is possible to investigate any accessible surface in animals or humans such as skin, mucous membranes or internal organs. ${ }^{20}$ OPS has been validated for quantitative measurements of microcirculatory parameters in an animal model compared to common intravital microscopy with fluorescent dyes. ${ }^{20}$ In humans, OPS has been validated in healthy volunteers before and after venous occlusion of the forearm, as well as in patients with sepsis. ${ }^{21}$

Here, we captured and examined video sequences of an unbranched part of an arteriole and venule with a length of $100 \mu \mathrm{m}$ and a maximal diameter of $50 \mu \mathrm{m}$ for RBC flow (FRBC) and RBC velocity (VRBC). Of the three video films taken at each time point, the one with the best quality was further used for calculation of functional capillary density (FCD) with an integrated calculating program (Capyscope ${ }^{\circledR}$; KK Technology, Brightham, UK).

OPS microscopy has a number of intrinsic limitations. In order to maximize the reproducibility within our study and for other researchers, we applied the following precautions: The piglets were paralyzed to reduce the spontaneous movements of the intestine and therefore potential errors of microcirculatory measurements. Analysis was performed off line in order to keep intervals between 
measurements identical. To avoid interindividual differences, one nonblinded investigator performed assessment and analysis of microcirculation data. Later, the video sequences were independently re-evaluated by four blinded investigators to prevent bias. The videos were categorized using the following semiquantitative scoring system:

Score 0: No capillaries visible.

Score 1: No or few capillaries visible, low velocity or no visible flow.

Score 2: Some capillaries visible, moderate velocity, visible flow.

Score 3: Many capillaries visible, high velocity, flow obvious.

\section{Setting}

Ten German Landrace neonatal piglets (mean bodyweight $2420 \mathrm{~g}$, mean age $2 \mathrm{~d}$ ) were used in this study. The animals received $0.02 \mathrm{mg}$ atropine (Atropin ${ }^{\circledR}$, Braun, Melsungen, Germany) and were sedated with azaperon (Stresnil ${ }^{\circledR}$, Janssen-Cilag, Baar, Switzerland, $8 \mathrm{mg} / \mathrm{kg}$ i.m.). The piglets received a continuous infusion of glucose $10 \%(10 \mathrm{ml} / \mathrm{kg} / \mathrm{h})$ via a peripheral venous access during the whole study period. Ketamine $(10 \mathrm{mg} / \mathrm{kg})$ was given i.m., followed by insertion of a $3.0 \mathrm{CH}$ endotracheal tube via tracheotomy. For continuous monitoring of hemodynamic parameters and blood sampling, a catheter (4 F; Argyle ${ }^{\circledR}$, Sherwood Medical, Tullamore, Ireland) was placed into the left carotid artery. Median laparotomy was performed to access the ileum. Analgesia and sedation were achieved with $0.3 \mathrm{mg} / \mathrm{kg} / \mathrm{h}$ midazolam (Dormicum ${ }^{\circledR}$, Braun) and $1 \mu \mathrm{g} / \mathrm{kg} / \mathrm{h}$ fentanyl (Fentany ${ }^{\circledR}$, Janssen Cilag). The piglets were paralyzed with $0.1 \mathrm{mg} / \mathrm{kg} / \mathrm{h}$ pancuronium (Pancuronium Curamed ${ }^{\circledR}$, Curamed, Karlsruhe, Germany). Rectal body temperature was recorded continuously and a temperature of $38.5^{\circ} \mathrm{C}$ was maintained with a heated mattress. Hemodynamic measurements included continuous monitoring of heart rate as well as systolic, mean, and diastolic pressures (Monitor: Solar $8000^{\circledR}$, Marquette Hellige Freiburg, Germany; Transducer: Medex System $^{\circledR}$, Medex, Carlsbad, CA, USA). Measurement of these parameters and assessment of microcirculation using OPS imaging $\left(\right.$ Cytoscan $\left.^{\circledR}\right)$ were performed simultaneously. At each time point, three different sites on the peritoneal surface of the ileum were recorded for $30 \mathrm{sec}$ at 10 frames/second. After a stabilization period of $30 \mathrm{~min}$ after the surgical procedure, each piglet received an intravenous bolus of $500 \mu \mathrm{g} / \mathrm{kg}$ E. coli LPS (O 111 B 04, Sigma-Aldrich Chemie GmbH, Munich, Germany). Five piglets received $24 \mu \mathrm{g} / \mathrm{kg} / \mathrm{h}$ rhAPC (Xigris ${ }^{\circledR}$, Eli Lilly) as a continuous intravenous infusion starting $30 \mathrm{~min}$ after LPS. The infusion was continued to the end of the study period. Five piglets received saline and served as controls. Hemodynamic and microcirculatory parameters (at three sites as described above) were assessed prior to endotoxemia (baseline, $0 \mathrm{~min}$ ) and every $30 \mathrm{~min}$ for a period of three hours $(30,60,90,120,150$, and $180 \mathrm{~min})$. At the same time points, blood samples were taken in which red blood cells (RBC), white blood cells (WBC) and platelets (PLT) and the hematocrit (Hct) were measured. No intervention such as volume resuscitation or inotropic support was given. After the study period, the piglets were euthanized with T $61^{\circledR}$ (embrutamide/tetracaine, Hoechst, Frankfurt/ Main, Germany). Laboratory evaluation was performed by blinded laboratory technicians. The Committee on Animal Research/State of Hesse approved the protocol of this study (Nr F. 133/04).

\section{Statistics}

Statistic analysis was performed with Sigma Stat ${ }^{\circledR}$ (SYSTAT Software Inc, Richmond, CA, USA) using a two-way repeated measure ANOVA with Bonferroni post-hoc pairwise comparison on the raw data. A $p<0.05$ was considered significant. Microcirculatory parameters and mean arterial blood pressure (MAP) were assigned a value of 0 after subjects died from hypotension. All data are displayed as mean values and \pm SEM.

\section{Results}

\section{Survival and bleeding complications}

Two animals in the control group died of septic shockinduced hypotension at 125 and $135 \mathrm{~min}$. None of the animals treated with rhAPC died during the study period. None of the animals in either group suffered from bleeding events, defined as macroscopic bleeding or an obvious extravasation of RBC from arterioles or venules.

\section{Hematology}

Hematocrit and hemoglobin levels as well as RBC count did not change significantly (Table 1 ). There was a trend to reduced platelet and white blood counts after the initiation of endotoxic shock in all animals. The most pronounced decline was observed in the control group, although the difference to the rhAPC group was not statistically significant (Table 1).

\section{Macrocirculation}

Whereas the MAP dropped dramatically in the control piglets (open circles in Figure 1), the decrease in animals which received rhAPC was not significant. From 90 min onwards, 
Table I Blood cell counts

\begin{tabular}{|c|c|c|c|c|c|c|c|c|}
\hline & $\begin{array}{l}\mathrm{Hb}(\mathrm{g} / \mathrm{dl}) \\
\text { baseline }\end{array}$ & $\begin{array}{l}\mathrm{Hb}(\mathrm{g} / \mathrm{dl}) \\
180 \mathrm{~min}\end{array}$ & $\begin{array}{l}\text { Hct (\%) } \\
\text { baseline }\end{array}$ & $\begin{array}{l}\text { Hct (\%) } \\
\text { I } 80 \mathrm{~min}\end{array}$ & $\begin{array}{l}\text { PLT (/nl) } \\
\text { baseline }\end{array}$ & $\begin{array}{l}\text { PLT (/nl) } \\
\text { I80 min }\end{array}$ & $\begin{array}{l}\text { WBC }(/ n l) \\
\text { baseline }\end{array}$ & $\begin{array}{l}\text { WBC (/nl) } \\
180 \mathrm{~min}\end{array}$ \\
\hline Vehicle & $6.86 \pm 2.79$ & $6.47 \pm 0.3$ & $21.4 \pm 9.37$ & $20.6 \pm 2.62$ & $766 \pm 215$ & $587 \pm 230$ & $8.08 \pm 2.19$ & $4.27 \pm 1.66$ \\
\hline rhAPC & $5.98 \pm 0.58$ & $6.7 \pm 0.8 \mathrm{I}$ & $17.9 \pm 2.25$ & $19.7 \pm 2.17$ & $845 \pm 189$ & $635 \pm 266$ & $7.84 \pm 1.67$ & $4.6 \pm 0.97$ \\
\hline
\end{tabular}

Notes: All values shown as mean \pm standard error of the mean. No statistically significant differences between controls and rhAPC were found. Baseline was set at $\mathrm{t} 0$, ie, immediately prior to LPS injection.

Abbreviations: $\mathrm{Hb}$, hemoglobin; Hct, hematocrit; PLT, platelets; rhAPC, recombinant activated protein C.

the difference between the treatment and the control groups was marked (Figure 1A) and statistically significant despite a considerable interindividual variability.

\section{Microcirculation}

We detected changes in the microcirculation as early as 30 min after LPS administration. The observed impairment of the microcirculation increased over time in the control group, whereas microcirculation was preserved in the animals receiving rhAPC (Figure 1B to D). Although the rhAPCmediated protection as measured by functional capillary density (FDC), a parameter for perfusion, did not reach statistical significance due to inter-individual variability, the decrease in FDC in the control animals was considerable (Figure 1B). As shown in Figure 1C, the velocity of capillary red blood cell flow (VRBC) was significantly higher in rhAPC-treated animals compared to the control group at 150 and $180 \mathrm{~min}$. In the late stages of the experiment, the VRBC was significantly reduced compared to baseline at $120 \mathrm{~min}$ and $180 \mathrm{~min}$ in control piglets.

Red blood cell flow (FRBC) was maintained over the complete study period of $180 \mathrm{~min}$ in the rhAPC group, whereas FRBC decreased in control animals. From $120 \mathrm{~min}$ onwards, FRBC was significantly higher in animals treated with rhAPC compared to controls.

In addition, video sequences recorded at different time points and under different treatment conditions were scored by four independent, blinded investigators. These volunteers were provided with one exemplary video for the semi-quantitative scores 0 to 3 with 0 being no flow with rarified capillaries and 3 standing for unimpaired flow with normal capillary density. Thereafter, 18 video sequences were assessed by each volunteer. The blinded assessors confirmed the results documented by the nonblinded investigator. Figure 2 shows the LPS-induced deterioration of microcirculation over the course of the study period as well as the reversal of this effect by rhAPC as per the blinded volunteers. One representative video for each condition (Normal microcirculation before LPS injection [t0], impaired microcirculation
[LPS alone], and improvement by treatment with rhAPC [LPS + rhAPC]) can be viewed online (see http://dovepress. com/submission_video_5863.php).

\section{Discussion}

In newborn piglets, we demonstrate impairment of the intestinal microcirculation early after induction of endotoxic shock and show that this can be prevented by treatment with rhAPC. Our data concur with another study that provided an insight into the visceral endothelial response to a sepsis trigger and underlined the importance of the intestine as a primary shock organ. ${ }^{21}$ Our study provides new affirmative data for the clinical observation that the use of protein $\mathrm{C}$ results in an improvement of sepsis-induced microcirculatory dysfunction. ${ }^{14,22}$

In accord with the findings of De Backer and colleagues, sepsis-induced alteration of the MAP was positively influenced by rhAPC. ${ }^{22}$ The De Backer study demonstrated a rapid increase in MAP shortly after infusion of rhAPC in patients with septic shock. In addition, a recent study by Wang and colleagues pointed out the beneficial effects of rhAPC on arterial blood pressure and microcirculation. ${ }^{23}$ Our study, which focused on the early phase of endotoxic shock, established that early intervention with rhAPC prevented a dramatic fall in blood pressure induced by injection of LPS. We did not measure the cardiac index, therefore we can only speculate that the preservation of the MAP may have partly been caused by a direct positive effect of rhAPC on cardiac output. However, it seems more likely that the improvement of the MAP was caused by an endothelial effect of rhAPC, for example by a reduction in vasodilatation in the treated animals compared to the controls or by a prevention of exaggerated endothelial inflammation and consequently reduced coagulability.

In fact, other groups as well as our own previously reported that both rhAPC and the zymogen human protein $\mathrm{C}$ concentrate (hPC) inhibit the induction of pro-inflammatory cytokines and thereby reduce sepsis-induced endothelial injury, resulting in a reduction in the incidence of microthrombosis. ${ }^{5}$ This reduction in microvascular thrombosis may play a role in the overall protection conferred by rhAPC. 
A: MAP

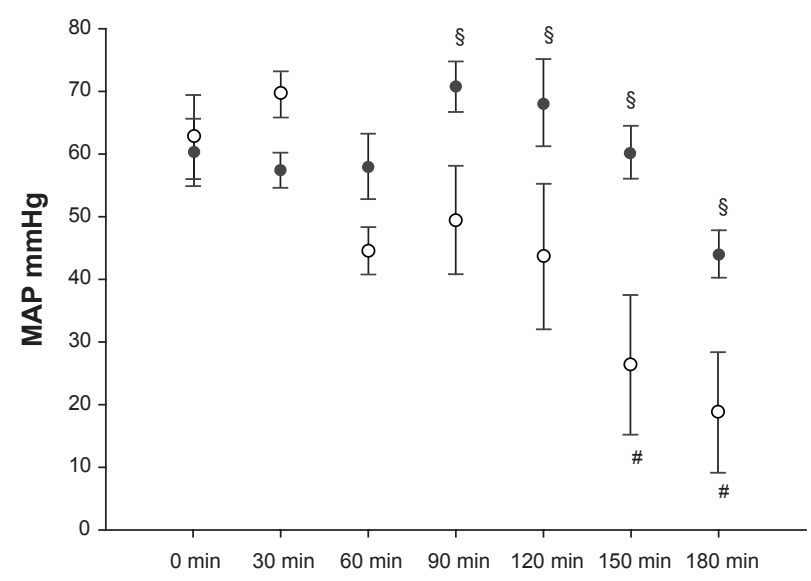

C: Velocity

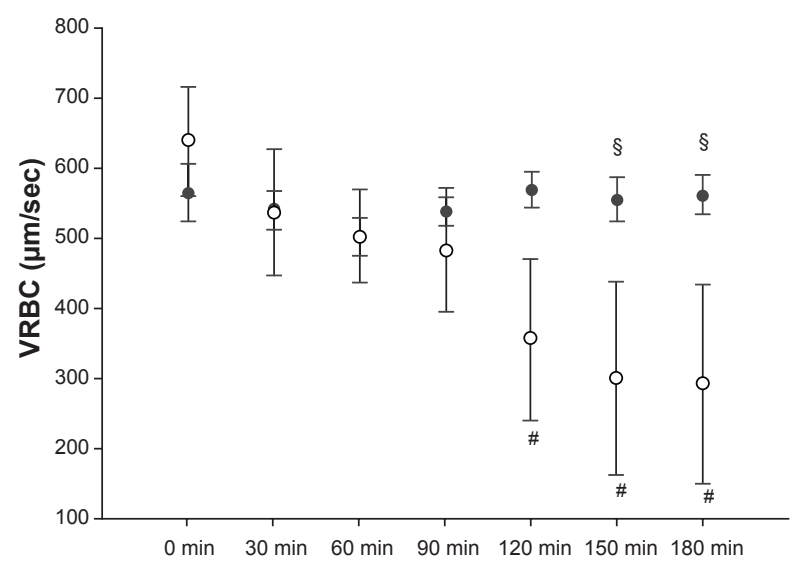

B: FCD

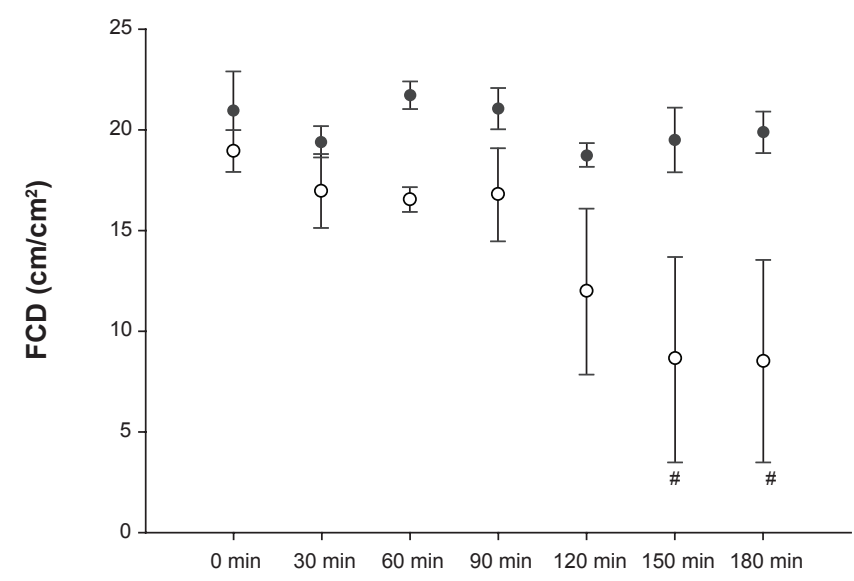

D: Flow

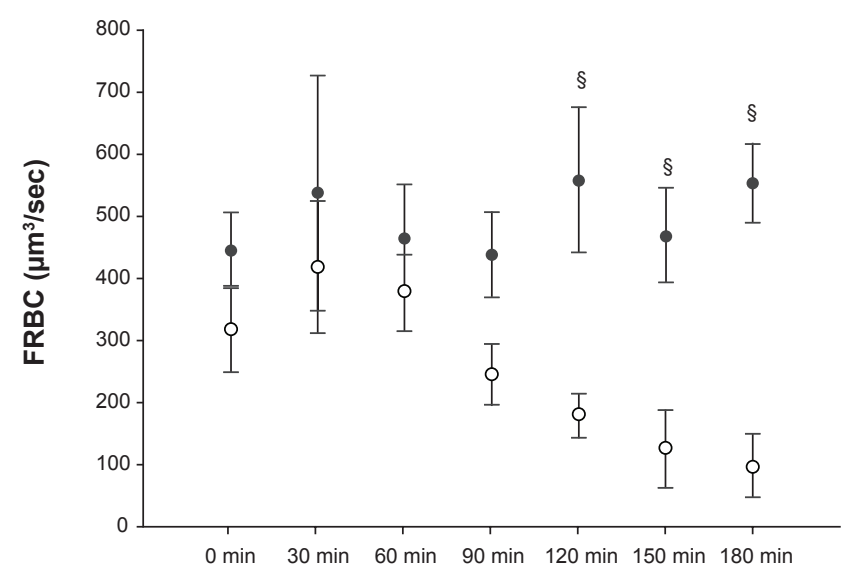

- APC

Controls

Figure I Macro- and microcirculatory effects of recombinant activated protein C (rhAPC). Endotoxic shock was induced by injection of $500 \mu \mathrm{g} / \mathrm{kg}$ LPS in I0 piglets at t0 ( 0 $\mathrm{min}$ ). A continuous infusion of $24 \mu \mathrm{g} / \mathrm{kg} / \mathrm{h}$ rhAPC (five animals, black circles) or vehicle (five animals, open circles) was started at 30 min.

Notes: All values shown as mean \pm standard error of the mean. \#, $\mathrm{p}<0.05$ for controls at later time points vs controls at 0 min. $\S$, $\mathrm{p}<0.05$ for rhAPC-treated piglets vs controls. A) mean arterial blood pressure (MAP) in $\mathrm{mmHg}$. B) functional capillary density $(\mathrm{FCD})$ in $\mathrm{cm}^{\mathrm{c}} \mathrm{cm}^{2}$. C) red blood cell velocity (VRBC) in $\mu \mathrm{m} / \mathrm{sec}$. D) red blood cell flow (FRBC) in $\mu \mathrm{m}^{3} / \mathrm{sec}$.

The major disadvantage in the clinical use of rhAPC in septic patients is the risk of life-threatening hemorrhage. In contrast with other publications in which hemorrhage following treatment with rhAPC was observed, there were no macro- or microscopic bleeding events in our study and $\mathrm{Hb}$ and Hct levels were maintained in treatment and control groups. Although our study does not allow any conclusions regarding the risk of hemorrhage and the safety of rhAPC in septic neonates because of a limited number of animals and a short observation period, we speculate that potential differences in bleeding events may have been due to the different APC dosing regimen employed in our study (infusion of $24 \mu \mathrm{g} / \mathrm{kg} / \mathrm{h}$ ) versus a bolus of 2 and $5 \mathrm{mg} / \mathrm{kg}$ used by Iba and colleagues. ${ }^{16}$ This regimen has been described by Russo and colleagues ${ }^{24}$ who treated pediatric cancer patients with severe ongoing sepsis with $24 \mu \mathrm{g} / \mathrm{kg} / \mathrm{h}$. Although these patients had a low platelet count (mean 9000/nl), none of them experienced bleeding events during treatment. However, these patients were not coagulopathic and therefore do not necessarily represent the common pediatric sepsis patient.

Although we found no bleeding in our study, there is no doubt that rhAPC induces significant bleeding when administered to patients, thereby limiting its use in adults and causing extreme reluctance to employ rhAPC in infants 
and children. ${ }^{8,9,25}$ As an alternative to rhAPC, there is strong evidence of sufficient endogenous activation of $\mathrm{hPC}$ in children with sepsis. ${ }^{26}$ We and others have shown that hPC is effective in the treatment of neonates and children with sepsis-induced purpura fulminans without increasing the risk of hemorrhage. ${ }^{14,26-28}$ In porcine animal models, however, activation of hPC is known to be less effective. Thus, a benefit was doubtful and we decided not to use it in this study.

Limitations of this study include the rather small number of subjects as well as the fact that the animal model requires the use of rhAPC as opposed to the clinically preferable zymogen $\mathrm{hPC}$. In addition, data obtained by OPS microscopy
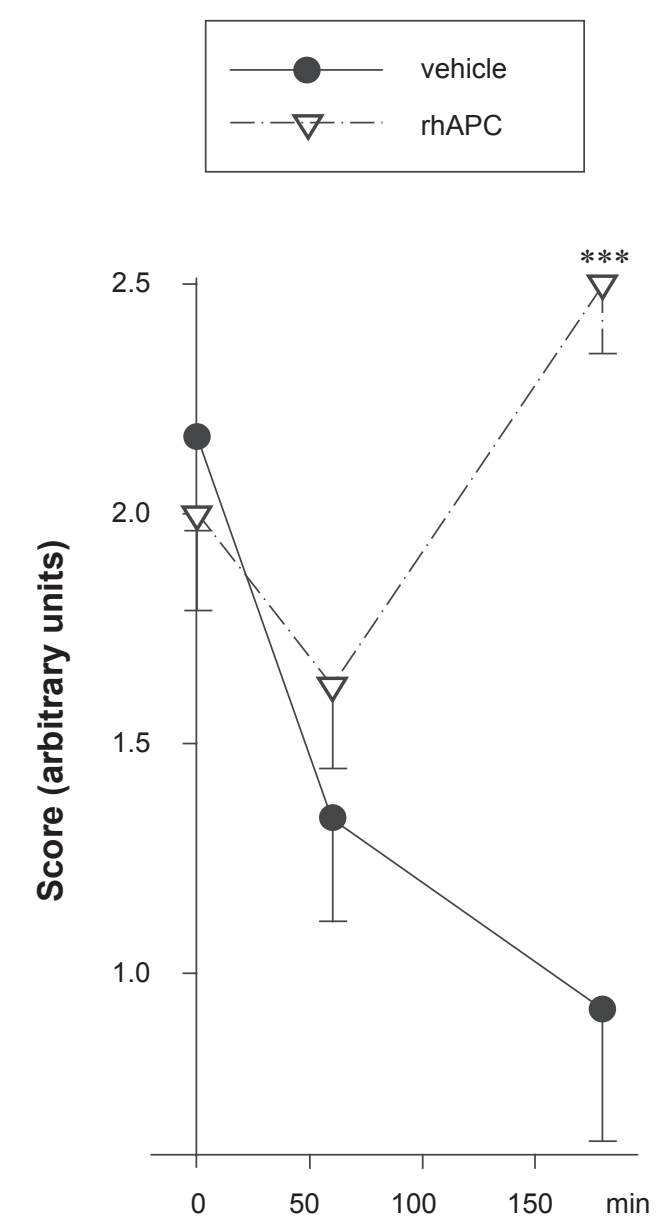

Figure 2 Amelioration of LPS-induced impairment of microcirculation. Microcirculation was assessed half-hourly by OPS-microscopy at three sites of the intestine in each of 10 piglets which had received $500 \mu \mathrm{g} / \mathrm{kg}$ LPS. The video sequences obtained during the three-hour study period were independently assessed by four blinded investigators using a semiquantitative scoring system. After having seen one representative video for each category, they applied the following scores to 18 sequences: score 0 , no visible capillaries; score I, very few visible capillaries, low velocity or no visible blood cell flow; score 2 , some visible capillaries, moderate velocity, visible blood cell flow; score 3, many visible capillaries, high velocity, blood cell flow obvious.

Notes: The mean scores are shown in the figure: \pm SEM; five piglets per group, four blinded assessors, and 18 videos; ***p $<0.00$ I for rhAPC- vs vehicle-treated piglets. Abbreviations: rhAPC, recombinant activated protein C; LPS, lipopolysaccharides; OPS, orthogonal polarization spectral imaging. have to be interpreted with caution, since although we employed an array of precautions (see Methods), it is impossible to eliminate all subjective elements from an OPS study. Nonetheless, our data present significant evidence for a beneficial effect of protein $\mathrm{C}$ on sepsis-induced deterioration of the macro- and microcirculation in an experimental model of neonatal septic shock. We show that microvascular perfusion is protected in the treatment group as measured by microcirculatory blood flow and functional capillary density. The findings of our study may encourage researchers to further explore protein $\mathrm{C}$ in neonatal diseases in which intestinal microcirculation is impaired.

\section{Acknowledgments}

We would like to thank Prof Philip Berger and Elizabeth Skuza for their help in data analysis and review of the manuscript. Dr Alex Veldman is a member of the Baxter Advisory Board and as such receives an honorarium. All other authors declare that there are no financial or other conflicts of interest. This study was not supported by any industrial grant.

\section{References}

1. Meadow W, Frain L, Ren Y, Lee G, Soneji S, Lantos J. Serial assessment of mortality in the neonatal intensive care unit by algorithm and intuition: certainty, uncertainty, and informed consent. Pediatrics. 2002;109(5):878-886.

2. Asaka S, Shibayama Y, Nakata K. Pathogenesis of focal and random hepatocellular necrosis in endotoxemia: microscopic observation in vivo. Liver. 2006;16:183-187.

3. Taylor FB Jr, Chang A, Esmon CT, D'Angelo A, Vigano-D'Angelo S, Blick KE. Protein C prevents the coagulopathic and lethal effects of Escherichia coli infusion in the baboon. J Clin Invest. 1987;79:918-925.

4. Kurosawa S, Esmon CT, Stearns-Kurosawa DJ. The soluble endothelial protein $\mathrm{C}$ receptor binds to activated neutrophils: involvement of proteinase-3 and CD11b/CD18. J Immunol. 2000;165:4697-4703.

5. Nold MF, Nold-Petry CA, Fischer D, et al. Activated protein C downregulates p38 mitogen-activated protein kinase and improves clinical parameters in an in-vivo model of septic shock. Thromb Haemost. 2007;98:1118-1126.

6. Taylor FB Jr, Stearns-Kurosawa DJ, Kurosawa S, et al. The endothelial cell protein $\mathrm{C}$ receptor aids in host defense against Escherichia coli sepsis. Blood. 2000;95:1680-1686.

7. White B, Schmidt M, Murphy C, Livingstone W, et al. Activated protein $\mathrm{C}$ inhibits lipopolysaccharide-induced nuclear translocation of nuclear factor kappaB (NF-kappaB) and tumour necrosis factor alpha (TNF-alpha) production in the THP-1 monocytic cell line. $\mathrm{Br} J$ Haematol. 2000;110:130-134.

8. Bernard GR, Vincent JL, Laterre PF, et al. Efficacy and safety of recombinant human activated protein $\mathrm{C}$ for severe sepsis. $N$ Engl $J$ Med. 2001;344:699-709.

9. Nadel S, Goldstein B, Williams MD, et al. Drotrecogin alfa (activated) in children with severe sepsis: a multicentre phase III randomised controlled trial. Lancet. 2007;369:836-843.

10. Albuali WJ, Singh RN, Fraser DD, Scott LA, Kornecki A. Drotrecogin alfa activated treatment in a neonate with sepsis and multi-organ failure. Saudi Med J. 2005;26:1289-1292.

11. Rawicz M, Sitkowska B, Rudzinska I, Kornacka MK, Bochenski P. Recombinant human activated protein $\mathrm{C}$ for severe sepsis in a neonate. Med Sci Monit. 2002;8:CS90-CS94. 
12. De Carolis MP, Polimeni V, Papacci P, Lacerenza S, Romagnoli C. Severe sepsis in a premature baby. protein c replacement therapy. Turk J Pediatr. 2008;50(4):405-408.

13. Yesilirmak DC, Kumral A, Tugyan K, et al. Effects of activated protein $\mathrm{C}$ on neonatal hypoxic ischemic brain injury. Brain Res. 2008; 1210:56-62.

14. Kreuz W, Veldmann A, Fischer D, Schlosser R, Volk WR, Ettingshausen CE. Neonatal sepsis: a challenge in hemostaseology. Semin Thromb Hemost. 1999;25:531-535.

15. Venkataseshan S, Dutta S, Ahluwalia J, Narang A. Low plasma protein C vaules predict mortality in low birth weight neonates with septicemia. Pediatr Infect Dis J. 2007;26:684-688.

16. Iba T, Kidokoro A, Fukunaga M, Nagakari K, Shirahama A, Ida Y. Activated protein $\mathrm{C}$ improves the visceral microcirculation by attenuating the leukocyte-endothelial interaction in a rat lipopolysaccharide model. Crit Care Med. 2005;33:368-372.

17. Genzel-Boroviczeny O, Strotgen J, Harris AG, Messmer K, Christ F. Orthogonal polarization spectral imaging (OPS): a novel method to measure the microcirculation in term and preterm infants transcutaneously. Pediatr Res. 2003;51:386-391.

18. Slaaf DW, Tangelder GJ, Reneman RS, Jager K, Bollinger A. A versatile incident illuminator for intravital microscopy. Int J Microcirc Clin Exp. 1987;6:391-397.

19. Gross JF, Aroesty J. Mathematical models of capillary flow: a critical review. Biorheology. 1972;9:225-264.

20. Langer S, Biberthaler P, Harris AG, Steinau HU, Messmer K. In vivo monitoring of microvessels in skin flaps: introduction of a novel technique. Microsurgery. 2001;21:317-324.
21. Biberthaler P, Langer S, Luchting B, Khandoga A, Messmer K In vivo assessment of colon microcirculation: comparison of the new OPS imaging technique with intravital microscopy. Eur J Med Res. 2001;6:525-534.

22. Boerma EC, Mathura KR, van der Voort PH, Spronk PE, Ince C. Quantifying bedside-derived imaging of microcirculatory abnormalities in septic patients: a prospective validation study. Crit Care. 2005;9: R601-R606.

23. De Backer, Verdant C, Chierego M, Koch M, Gullo A, Vincent JL. Effects of drotrecogin alfa activated on microcirculatory alterations in patients with severe sepsis. Crit Care Med. 2006;34:1918-1924.

24. Wang Z, Su F, Rogiers P, Vincent JL. Beneficial effects of recombinant activated protein $\mathrm{C}$ in a ewe model of septic shock. Crit Care. 2007;35(11):2594-2600.

25. Russo G, La Spina M, Disma N, Astuto M. Drotrecogin alfa activated as a treatment for severe sepsis in pediatric cancer. Bone Marrow Transplant. 2006;38:575-576.

26. Kylat RI, Ohlsson A. Recombinant human activated protein $\mathrm{C}$ for severe sepsis in neonates. Cochrane Database Syst Rev. 2006;2:CD005385.

27. de Kleijn ED, de Groot R, Hack CE, et al. Activation of protein $C$ following infusion of protein $\mathrm{C}$ concentrate in children with severe meningococcal sepsis and purpura fulminans: a randomized, doubleblinded, placebo-controlled, dose-finding study. Crit Care Med. 2003;31:1839-1847.

28. White B, Livingstone W, Murphy C, Hodgson A, Rafferty M, Smith OP. An open-label study of the role of adjuvant hemostatic support with protein $\mathrm{C}$ replacement therapy in purpura fulminans-associated meningococcemia. Blood. 2000;96:3719-3724
Vascular Health and Risk Management

\section{Publish your work in this journal}

Vascular Health and Risk Management is an international, peerreviewed journal of therapeutics and risk management, focusing on concise rapid reporting of clinical studies on the processes involved in the maintenance of vascular health; the monitoring, prevention and treatment of vascular disease and its sequelae; and the involvement of

\section{Dovepress}

metabolic disorders, particularly diabetes. This journal is indexed on PubMed Central and MedLine. The manuscript management system is completely online and includes a very quick and fair peer-review system, which is all easy to use. Visit http://www.dovepress.com/ testimonials.php to read real quotes from published authors 